\title{
Effect of balloon guide catheter utilization on contact aspiration thrombectomy
}

\author{
Dong-Hun Kang, MD, ${ }^{1}$ Byung Moon Kim, MD, ${ }^{2}$ Ji Hoe Heo, MD, ${ }^{3}$ Hyo Suk Nam, MD, ${ }^{3}$ \\ Young Dae Kim, MD, ${ }^{3}$ Yang-Ha Hwang, MD, ${ }^{4}$ Yong-Won Kim, MD, ${ }^{4}$ Yong-Sun Kim, MD, ${ }^{5}$ \\ Dong Joon Kim, MD, ${ }^{2}$ Hyo Sung Kwak, MD, ${ }^{6}$ Hong Gee Roh, MD, ${ }^{7}$ Young-Jun Lee, MD, ${ }^{8}$ and \\ Sang Heum Kim, MD9
}

Departments of ${ }^{1}$ Neurosurgery and Radiology, ${ }^{4}$ Neurology, and ${ }^{5}$ Radiology, School of Medicine, Kyungpook National University, Daegu; Departments of ${ }^{2}$ Radiology and ${ }^{3}$ Neurology, Severance Stroke Center, Severance Hospital, Yonsei University College of Medicine, Seoul; ${ }^{6}$ Department of Radiology, Chonbuk National University Medical School and Hospital, Jeonju; ${ }^{7}$ Department of Radiology, Konkuk University Medical Center, Seoul; ' ${ }^{8}$ Department of Radiology, Hanyang University Medical School and Hospital, Seoul; and ' Department of Radiology, CHA Bundang Medical Center, CHA University, Seongnam, South Korea

\begin{abstract}
OBJECTIVE The role of the balloon guide catheter (BGC) has not been evaluated in contact aspiration thrombectomy (CAT) for acute stroke. Here, the authors aimed to test whether the BGC was associated with recanalization success and good functional outcome in CAT.
\end{abstract}

METHODS All patients who had undergone CAT as the first-line treatment for anterior circulation intracranial large vessel occlusion were retrospectively identified from prospectively maintained registries for six stroke centers. The patients were dichotomized into BGC utilization and nonutilization groups. Clinical findings, procedural details, and recanalization success rates were compared between the two groups. Whether the BGC was associated with recanalization success and functional outcome was assessed.

RESULTS A total of 429 patients (mean age $68.4 \pm 11.4$ years; M/F ratio $215: 214$ ) fulfilled the inclusion criteria. A BGC was used in $45.2 \%$ of patients. The overall recanalization and good outcome rates were $80.2 \%$ and $52.0 \%$, respectively. Compared to the non-BGC group, the BGC group had a significantly reduced number of CAT passes (2.6 \pm 1.6 vs $3.4 \pm 1.5$ ), shorter puncture-to-recanalization time ( $56 \pm 27$ vs $64 \pm 35$ minutes), lower need for the additional use of thrombolytics (1.0\% vs $8.1 \%$ ), and less embolization to a distal or different site ( $0.5 \%$ vs $3.4 \%)$. The BGC group showed significantly higher final $(89.2 \%$ vs $72.8 \%)$ and first-pass $(24.2 \%$ vs $8.1 \%)$ recanalization success rates. After adjustment for potentially associated factors, BGC utilization remained independently associated with recanalization (OR 4.171, 95\% $\mathrm{Cl} 1.523-11.420)$ and good functional outcome (OR 2.103, 95\% Cl 1.225-3.612).

CONCLUSIONS BGC utilization significantly increased the final and first-pass recanalization rates and remained independently associated with recanalization success and good functional outcome.

https://thejns.org/doi/abs/10.3171/2018.6.JNS181045

KEYWORDS acute stroke; aspiration catheter; balloon guide catheter; thrombectomy; vascular disorders; interventional neurosurgery

$\mathrm{R}$ ANDOMIZED controlled trials (RCTs) have shown the safety and efficacy of endovascular thrombectomy (EVT) in patients with acute stroke due to intracranial large vessel occlusion (LVO) compared with a control group. ${ }^{1,3,59,18}$ In addition to the selection of suitable patients, an increased recanalization rate and shortened onset-to-recanalization time are two key factors for good clinical outcomes after EVT. ${ }^{6,15}$
Investigations using in vitro and animal stroke models have suggested that flow arrest with a balloon guide catheter (BGC) reduces the risk of distal embolization and increases the flow reversal effect compared with a conventional guide catheter. ${ }^{4,8}$ These effects associated with the use of a BGC seemed to lead to an increased recanalization rate and simplified EVT procedure by reducing the number of thrombectomy device passes and the need for

ABBREVIATIONS ASPECTS = Alberta Stroke Program Early CT Score; BGC = balloon guide catheter; $C A T$ = contact aspiration thrombectomy; $C R F=$ case report form; EVT = endovascular thrombectomy; ICA = internal carotid artery; $\mathrm{LVO}=$ large vessel occlusion; $\mathrm{MCA}=$ middle cerebral artery; $\mathrm{mRS}=$ modified Rankin Scale; $\mathrm{mTICl}=$ modified Thrombolysis in Cerebral Infarction; NIHSS = National Institutes of Health Stroke Scale; OPT = onset-to-puncture time; PRT = puncture-to-recanalization time; RCT = randomized controlled trial; tPA = tissue plasminogen activator.

SUBMITTED April 17, 2018. ACCEPTED June 11, 2018.

INCLUDE WHEN CITING Published online November 23, 2018; DOI: 10.3171/2018.6.JNS181045. 
the use of thrombolytics for distal emboli. Two recent clinical studies have also indicated that the utilization of BGC was associated with recanalization success and a shorter procedure time in stent retriever thrombectomy. ${ }^{16,20}$ Therefore, BGC use is generally recommended in stent retriever thrombectomy. However, those studies lacked independent adjudication of the reperfusion grade (defined by the modified Thrombolysis in Cerebral Infarction [mTICI] grade) and did not evaluate the independent association of BGC utilization with recanalization success.

Recently, in a RCT comparing contact aspiration thrombectomy (CAT) with the use of a stent retriever for first-line thrombectomy in acute ischemic stroke, CAT has been shown to be a safe and effective method of mechanical thrombectomy for the removal of clots. ${ }^{14,21}$ Nevertheless, to date, there has been only a single small case series investigating the combined use of BGC and CAT in 31 patients. ${ }^{19}$

Given the findings of previous experimental investigations and several clinical case series, we hypothesized that the use of a BGC would simplify the procedure, reduce the puncture-to-recanalization time (PRT), and increase the recanalization success (defined as mTICI grade $2 b-3$ ) rate not only in stent retriever thrombectomy, but also in CAT. The purpose of this study was to test whether utilization of BGC in CAT was independently associated with recanalization success and good clinical outcome in a large patient cohort obtained from the prospectively maintained registries of six comprehensive stroke centers.

\section{Methods \\ Patient Enrollment}

The institutional review board at every participating hospital approved this study and waived the requirement for informed consent for study inclusion based on the retrospective study design.

We identified consecutive patients who had undergone CAT using the Penumbra System (Penumbra Inc.) or a large-bore intermediate catheter for acute ischemic stroke due to relevant intracranial internal carotid artery (ICA) or middle cerebral artery (MCA) $\mathrm{M}_{1}$ or proximal $\mathrm{M}_{2}$ segment occlusion, and who had functional outcomes (modified Rankin Scale [mRS] score 0-6) available at 3 months after operation. Patient data were obtained from the prospectively maintained registries for six comprehensive stroke centers for the period between January 2011 and December 2015. Enrollment criteria for inclusion in the study were as follows: 1) age $\geq 18$ years, 2) initial National Institutes of Health Stroke Scale (NIHSS) score $\geq 4$, 3) onset-to-puncture time (OPT) $\leq 600$ minutes, 4) $\mathrm{mRS}$ score of 0 or 1 before the qualifying stroke, 5) recanalization success assessable on catheter angiogram, and 6) documented intracranial ICA or $\mathrm{M}_{1}$ or $\mathrm{M}_{2}$ occlusion on CT, MRI, or catheter angiography. Patients with tandem atherosclerotic or dissecting cervical ICA occlusion accompanied by intracranial LVO were included. Patients with posterior circulation LVO or multifocal LVO (bilateral anterior or involvement of both anterior and posterior circulations) were excluded.

\section{Contact Aspiration Thrombectomy}

For those patients eligible for intravenous tissue plasminogen activator (tPA) treatment, tPA $(0.9 \mathrm{mg} / \mathrm{kg})$ was administered. The CAT procedures were performed with the patient under local anesthesia with or without conscious sedation. The technical details of CAT have been described elsewhere. ${ }^{13-15}$ Briefly, A 6-Fr guide sheath (Shuttle, Cook Medical; NeuronMax, Penumbra Inc.) or 8-Fr (Merci, Stryker Neurovascular) or 9-Fr BGC (Optimo, Tokai Medical; Cello, Medtronic Neurovascular) was used as a guide catheter. Once the guide catheter was optimally positioned in the distal cervical vasculature, a large-bore aspiration catheter (Penumbra reperfusion catheter, Penumbra Inc.; Navien distal access catheter, Medtronic Neurovascular; Revive distal access catheter, Codman) was advanced as close as possible to the proximal end of the thrombus using a coaxial technique with a 0.021 - to 0.027 -inch inner lumen microcatheter over a microwire. CAT was then performed with manual aspiration using a $20-$ or $50-\mathrm{ml}$ syringe. More specifically, a 50-ml syringe was used in the ICA or $\mathrm{M}_{1}$ occlusion, and a $20-\mathrm{ml}$ syringe was selectively used in the $\mathrm{M}_{2}$ occlusions. A Penumbra reperfusion catheter was predominantly used for CAT in all centers during the study period. The use of a BGC depended on the protocol at each participating site, not each operator's preference. Specifically, two centers had used the BGC in almost all cases since its introduction early in 2012, whereas the other four centers had not used the BGC at all during the study period. The tortuosity of the relevant carotid artery little affected whether a BGC was used or not. Except for BGC use, the CAT tools and techniques were similar across all participating centers.

In cases in which a BGC was used, the balloon of the BGC was inflated and then a Penumbra reperfusion catheter was cautiously retrieved under constant aspiration with a 50-ml syringe. This process was repeated until an mTICI grade of $2 b$ or 3 was achieved. The decision to stop the EVT procedure or to switch to or simultaneously use a stent retriever was determined by the operator, who took into consideration the occlusion etiology, clinical or patient conditions, etc.

\section{Data Collection and Assessment}

All data, including clinical and laboratory findings, were obtained from the prospectively maintained registries for acute stroke at each participating hospital and then entered into the predefined case report form (CRF). Procedural details, including complications during EVT, were obtained from the prospectively maintained neurointerventional database at each participating center and were also entered into the CRF. The CRFs were anonymized and then sent to a central core laboratory. All imaging data, including pretreatment nonenhanced CT, CT angiography and/or diffusion-weighted MRI with MR angiography, catheter angiography during the CAT, and follow-up CT or MRI, were anonymized and sent to the central core laboratory as Digital Imaging and Communications in Medicine (DICOM) files. Two neuroradiologists independently assessed the images for the Alberta Stroke Program Early CT Score (ASPECTS), and two interventional neuroradiologists independently assessed whether 


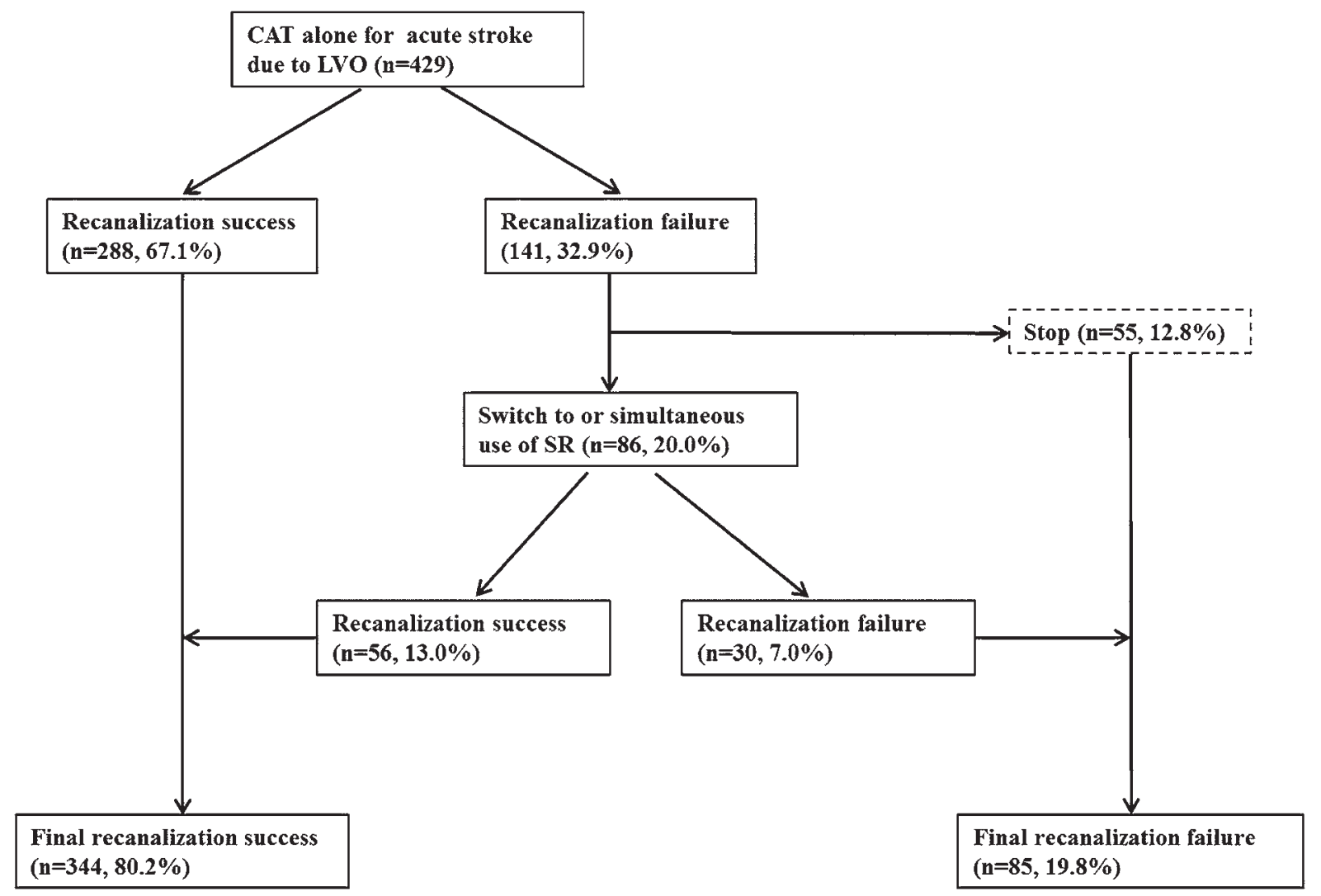

FIG. 1. Flowchart of contact aspiration for the first-line treatment of acute stroke.

recanalization success was achieved on the catheter angiography during the CAT. Those reviewers were blind to clinical outcomes. Recanalization success was defined as mTICI grade $2 \mathrm{~b}$ or 3 on the final control angiogram. Discrepant cases were resolved by consensus between raters who were still blinded to both the clinical outcomes and the findings on follow-up CT or MRI.

\section{Outcome Measurement}

The rates of recanalization success and good functional outcomes were evaluated in all patients who fulfilled inclusion criteria. A good outcome was defined as $\mathrm{mRS}$ score $0-2$ at 3 months. Patients were dichotomized into two groups according to procedure: CAT with BGC (BGC group) and without BGC (non-BGC group). Then, we compared the clinical and laboratory findings and procedural details, including the number of CAT passes, rates of recanalization and good outcome, and PRT if recanalization was successful, between those two groups. Finally, we tested whether BGC utilization remained independently associated with recanalization and clinical outcome after adjustment for other potentially associated factors.

\section{Statistical Analysis}

All statistical analyses were performed using IBM SPSS Statistics version 23 (IBM Corp.). All categorical variables were presented as numbers and frequencies (\%), and continuous variables were presented as the mean \pm standard deviation. In the univariate analysis, chi-square tests, Fisher's exact tests, Student t-tests, and Mann-Whitney U-tests were used as appropriate to identify factors associated with recanalization success and to compare clinical variables and procedural details between the BGC and non-BGC groups. Multivariate binary logistic regression analysis was performed to test whether utilization of a BGC remained independently associated with recanalization and good outcome after adjustment for other factors. We included in the binary logistic regression analysis those variables that showed potential association in the univariate analysis $(p<0.20)$. We assessed the model's goodness of fit with the Hosmer-Lemeshow test.

A $p$ value of less than 0.05 was considered significant. For multivariate analyses, the odds ratio is presented with the $95 \%$ confidence interval.

\section{Results}

Among 955 patients who had undergone EVT for acute stroke due to intracranial ICA or MCA $\left(\mathrm{M}_{1}\right.$ or $\left.\mathrm{M}_{2}\right)$ occlusion using a stent retriever, CAT, or both, 429 patients (mean age $68.4 \pm 11.4$ years, M/F ratio 215:214) fulfilled the study inclusion criteria.

A BGC was used in $45.2 \%$ of patients. The overall recanalization and good outcome rates were $80.2 \%$ and $52.0 \%$, respectively. Recanalization was achieved with CAT alone in $67.1 \%$ of patients and after a switch to or the simultaneous use of a stent retriever in $13.0 \%$ of patients (Fig. 1). Compared to the non-BGC group, the BGC group had a higher NIHSS score, more dyslipidemia, more atrial 
TABLE 1. Comparison of baseline characteristics of 429 patients grouped according to utilization of a BGC

\begin{tabular}{lccr}
\hline \multicolumn{1}{c}{ Parameter } & $\begin{array}{c}\text { Non-BGC } \\
\text { Group }\end{array}$ & $\begin{array}{c}\text { BGC } \\
\text { Group }\end{array}$ & $\begin{array}{c}\text { p } \\
\text { Value }\end{array}$ \\
\hline No. of patients & 235 & 194 & \\
\hline Age in yrs, mean \pm SD & $68.6 \pm 11.5$ & $68.2 \pm 11.4$ & 0.762 \\
\hline Male, no. (\%) & $113(48.1)$ & $102(52.6)$ & 0.383 \\
\hline Hypertension, no. (\%) & $153(65.1)$ & $120(61.9)$ & 0.545 \\
\hline Diabetes, no. (\%) & $60(25.5)$ & $45(23.2)$ & 0.652 \\
\hline Dyslipidemia, no. (\%) & $52(22.1)$ & $71(36.6)$ & 0.001 \\
\hline Smoking, no. (\%) & $80(34.0)$ & $58(29.9)$ & 0.406 \\
\hline CAOD, no. (\%) & $29(12.3)$ & $28(14.4)$ & 0.569 \\
\hline Atrial fibrillation, no. (\%) & $111(47.2)$ & $114(58.8)$ & 0.020 \\
\hline Baseline NIHSS score, median & $14 \pm 7$ & $16 \pm 8$ & $<0.001$ \\
$\quad \pm$ IQR & & & \\
\hline ASPECTS, median \pm IQR & $8 \pm 1$ & $8 \pm 1$ & 0.526 \\
\hline IV tPA, no. (\%) & $119(50.6)$ & $91(46.9)$ & 0.497 \\
\hline Tandem occlusion, no. (\%) & $15(6.4)$ & $19(9.8)$ & 0.212 \\
\hline Distal ICA involvement, no. (\%) & $48(20.4)$ & $76(39.2)$ & $<0.001$ \\
\hline M ${ }_{2}$ occlusion, no. (\%) & $39(16.6)$ & $8(4.1)$ & $<0.001$ \\
\hline Carotid artery stenting, no. (\%) & $11(4.7)$ & $8(4.1)$ & 0.818 \\
\hline
\end{tabular}

$\mathrm{CAOD}=$ coronary artery occlusive disease; $\mathrm{IQR}=$ interquartile range; IV = intravenous.

Boldface type indicates statistical significance.

fibrillation, more distal ICA involvement, and less $\mathrm{M}_{2}$ occlusion (Table 1). BGC utilization significantly reduced the number of CAT passes $(2.6 \pm 1.6$ vs $3.4 \pm 1.5, \mathrm{p}<$ $0.001)$, PRT ( $56 \pm 27$ vs $64 \pm 35$ minutes, $\mathrm{p}=0.018)$, need for the additional use of thrombolytics $(1.0 \%$ vs $8.1 \%, \mathrm{p}=$ $0.001)$, and embolization to a distal or different site $(0.5 \%$ vs $3.4 \%, p=0.045$; Table 2 ). The BGC group showed significantly higher final recanalization $(89.2 \%$ vs $72.8 \%$, $\mathrm{p}<0.001)$ and first-pass recanalization $(24.2 \%$ vs $8.1 \%$, $\mathrm{p}<0.001)$ success rates and good outcome rate $(60.3 \%$ vs $45.1 \%, \mathrm{p}=0.001)$. BGC utilization remained independently associated with recanalization (OR 4.171, 95\% CI 1.523-11.420, $\mathrm{p}=0.005$; Table 3 ) and good functional outcome (OR 2.103, 95\% CI 1.225-3.612; Table 4).

\section{Discussion}

The major findings of this study are as follows: 1) BGC utilization reduced the number of CAT passes, embolization to a distal or different site, and the need for the additional use of thrombolytics; 2) the BGC significantly increased the final recanalization and first-pass recanalization rates; and 3) the $\mathrm{BGC}$ was independently associated with a good outcome.

Based on the results of five RCTs, most guidelines recommend EVT using a stent retriever for the first-line treatment of acute stroke. ${ }^{1,3,5,9,18}$ However, a recent RCT showed that there were no significant differences in the rates of recanalization and good outcomes at 3 months between CAT and stent retriever thrombectomy. ${ }^{14}$ In that trial, BGC use was recommended in cases of thrombectomy using a stent retriever, but not with CAT.
TABLE 2. Comparison of outcomes between patients grouped according to utilization of a BGC

\begin{tabular}{|c|c|c|c|}
\hline Parameter & $\begin{array}{l}\text { Non-BGC } \\
\text { Group }\end{array}$ & $\begin{array}{l}\text { BGC } \\
\text { Group }\end{array}$ & $\begin{array}{c}\mathrm{p} \\
\text { Value }\end{array}$ \\
\hline No. of patients & 235 & 194 & \\
\hline OPT in mins, mean \pm SD & $289 \pm 147$ & $302 \pm 178$ & 0.460 \\
\hline $\mathrm{PRT}$ in mins, mean $\pm \mathrm{SD}$ & $64 \pm 35$ & $56 \pm 27$ & 0.018 \\
\hline No. of CAT passes, mean \pm SD & $3.4 \pm 1.5$ & $2.6 \pm 1.6$ & $<0.001$ \\
\hline $\begin{array}{l}\text { Embolism to distal or different } \\
\text { site, no. (\%) }\end{array}$ & $8(3.4)$ & $1(0.5)$ & 0.045 \\
\hline Additional urokinase, no. (\%) & $19(8.1)$ & $2(1.0)$ & 0.001 \\
\hline Additional GP, no. (\%) & 31 (13.2) & $20(10.3)$ & 0.373 \\
\hline Recanalization success, no. (\%) & $171(72.8)$ & $173(89.2)$ & $<0.001$ \\
\hline First-pass recanalization, no. (\%) & $19(8.1)$ & $47(24.2)$ & $<0.001$ \\
\hline Good outcome at 3 mos, no. (\%) & $106(45.1)$ & $117(60.3)$ & 0.001 \\
\hline HI type 1, no. (\%) & $35(14.9)$ & $28(14.4)$ & 0.999 \\
\hline HI type 2, no. (\%) & $10(4.3)$ & $10(5.2)$ & 0.819 \\
\hline PH type 1, no. (\%) & $20(8.5)$ & $10(5.2)$ & 0.189 \\
\hline PH type 2, no. (\%) & $11(4.7)$ & $5(2.6)$ & 0.311 \\
\hline Mortality, no. (\%) & $17(7.2)$ & $7(3.6)$ & 0.139 \\
\hline
\end{tabular}

$\mathrm{GP}=$ glycoprotein Ilb/IIla inhibitor; $\mathrm{HI}=$ hemorrhagic infarct; $\mathrm{PH}=$ parenchymal hematoma.

Boldface type indicates statistical significance.

There have been a few experimental and clinical studies on the role of BGC in mechanical thrombectomy. $4,8,16,20$ In those studies, the use of $\mathrm{BGC}$ reduced the risk of distal embolization during retrieval of the stent retriever. To our knowledge, however, only a single case series consisting of 31 patients has reported on the combined use of BGCs and CAT, with results showing a $96.8 \%$ recanalization rate and $51.6 \%$ of patients having good outcomes at 3 months. ${ }^{19}$

In the present study, BGC utilization not only increased the final and the first-pass recanalization rates, but also reduced the number of CAT passes, the need for adjunctive thrombolytics to lyse emboli in distal cerebral arteries, and the PRT. Two previous clinical studies using BGCs in stent retriever thrombectomy showed results similar to those in our study. Given our results, BGC seems to exhibit its helpful effects not only in stent retriever thrombectomy, but also in CAT.

For removal of the occluding clots of LVOs, the aspiration catheter has a mechanism of action different from that of a stent retriever. The BGC has been far less frequently used in CAT; therefore, its effectiveness in this context has not been well evaluated. The strengths of the present study are not only its comparison of BGC utilization with BGC nonuntilization, but also its assessment of the effect of BGC on recanalization together with other potential confounding factors in a multivariate analysis. BGC utilization remained independently associated with recanalization success.

Besides the prevention of distal embolization, recent reviews have suggested another positive effect of the use of BGC in mechanical thrombectomy. ${ }^{10,12,13,22}$ Two primary factors determine how much force will be required to remove the clot: the impaction force and the combined 
TABLE 3. Predictors for recanalization success

\begin{tabular}{|c|c|c|c|c|}
\hline Variable & Recanalization Failure & Recanalization Success & $p_{1}$ Value & $\mathrm{p}_{2}$ Value $(\mathrm{OR}, 95 \% \mathrm{Cl})$ \\
\hline Age in yrs, mean \pm SD & $67.3 \pm 13.0$ & $68.7 \pm 11.0$ & 0.350 & \\
\hline Male, no. $(\%)$ & $36(42.4)$ & $179(52.0)$ & 0.117 & 0.349 \\
\hline Hypertension, no. (\%) & $55(64.7)$ & $218(63.4$ & 0.900 & \\
\hline Diabetes, no. (\%) & $28(32.9)$ & $77(22.4)$ & 0.049 & 0.072 \\
\hline Dyslipidemia, no. (\%) & $18(21.2)$ & $105(30.5)$ & 0.108 & 0.091 \\
\hline Smoking, no. (\%) & $26(30.6)$ & $112(32.6)$ & 0.796 & \\
\hline CAOD, no. $(\%)$ & $12(14.1)$ & $45(13.1)$ & 0.858 & \\
\hline Atrial fibrillation, no. (\%) & $40(47.1)$ & $176(51.2)$ & 0.277 & \\
\hline Baseline NIHSS score, median \pm IQR & $15 \pm 7$ & $15 \pm 8$ & 0.403 & \\
\hline ASPECTS, median \pm IQR & $8 \pm 1$ & $8 \pm 1$ & 0.994 & \\
\hline IV tPA, no. (\%) & $38(44.7)$ & $172(50.0)$ & 0.399 & \\
\hline $\mathrm{OPT}$ in mins, mean $\pm \mathrm{SD}$ & $269 \pm 114$ & $298 \pm 167$ & 0.148 & 0.562 \\
\hline Tandem occlusion, no. (\%) & $6(7.1)$ & $28(8.1)$ & 0.999 & \\
\hline Distal ICA involvement, no. (\%) & $29(34.1)$ & $95(27.6)$ & 0.285 & \\
\hline BGC & $21(24.7)$ & $173(50.3)$ & $<0.001$ & $0.005(4.171,1.523-11.420)$ \\
\hline Carotid artery stenting, no. (\%) & $1(1.2)$ & $18(5.2)$ & 0.141 & 0.920 \\
\hline No. of CAT passes, mean \pm SD & $4.1 \pm 1.7$ & $2.8 \pm 1.5$ & $<0.001$ & $0.007(0.734,0.587-0.919)$ \\
\hline Embolism to distal or different site, no. (\%) & $4(4.7)$ & $5(1.5)$ & 0.090 & $0.009(0.139,0.032-0.612)$ \\
\hline Additional urokinase, no. (\%) & $9(10.6)$ & $12(3.5)$ & 0.012 & $0.001(0.186,0.067-0.517)$ \\
\hline Additional GP, no. (\%) & $10(11.8)$ & $41(11.9)$ & 0.999 & \\
\hline
\end{tabular}

force of friction and adhesion between the thrombus and the vessel wall. The impaction force is determined by the pressure gradient across the thrombus. Therefore, lower systemic blood pressure acting on the proximal thrombus and better retrograde collateral flow will result in a smaller pressure gradient across the occluding thrombus. Inflation of a BGC can markedly reduce the systemic blood pressure acting on the proximal clot face, resulting in a decrease

TABLE 4. Predictors for good outcome

\begin{tabular}{|c|c|c|c|c|}
\hline Variable & mRS Score 3-6 & mRS Score 0-2 & $p_{1}$ Value & $\mathrm{p}_{2}$ Value $(\mathrm{OR}, 95 \% \mathrm{Cl})$ \\
\hline Age in yrs, mean \pm SD & $72.0 \pm 9.3$ & $66.0 \pm 12.1$ & $<0.001$ & $<0.001(0.947,0.925-0.971)$ \\
\hline Male, no. $(\%)$ & $80(45.5)$ & $135(53.4)$ & 0.117 & 0.705 \\
\hline Hypertension, no. (\%) & $117(66.5)$ & $156(61.7)$ & 0.359 & \\
\hline Diabetes, no. (\%) & $56(31.8)$ & $49(19.4)$ & 0.004 & 0.078 \\
\hline Dyslipidemia, no. (\%) & $45(25.6)$ & $78(30.8)$ & 0.278 & \\
\hline Smoking, no. (\%) & $56(31.8)$ & $82(32.4)$ & 0.917 & \\
\hline CAOD, no. (\%) & $32(18.2)$ & $25(9.9)$ & 0.014 & $0.044(0.492,0.246-0.982)$ \\
\hline Atrial fibrillation, no. (\%) & $92(52.3)$ & $133(52.6)$ & 0.999 & \\
\hline Baseline NIHSS score, median \pm IQR & $17 \pm 7$ & $14 \pm 8$ & $<0.001$ & $<0.001(0.854,0.811-0.899)$ \\
\hline ASPECTS, median $\pm I Q R$ & $8 \pm 1$ & $8 \pm 1$ & 0.858 & \\
\hline IV tPA, no. (\%) & $79(44.9)$ & $131(51.8)$ & 0.170 & 0.339 \\
\hline OPT in mins, mean \pm SD & $305 \pm 161$ & $289 \pm 163$ & 0.345 & \\
\hline Tandem occlusion, no. (\%) & $21(11.9)$ & $13(5.1)$ & 0.017 & $0.024(0.342,0.135-0.867)$ \\
\hline Distal ICA involvement, no. (\%) & $58(33.0)$ & $66(26.1)$ & 0.131 & 0.868 \\
\hline BGC & $63(35.8)$ & $131(51.8)$ & 0.001 & $0.007(2.103,1.225-3.612)$ \\
\hline Carotid artery stenting, no. (\%) & $10(5.7)$ & $9(3.6)$ & 0.343 & \\
\hline No. of CAT passes, mean \pm SD & $3.7 \pm 1.6$ & $2.6 \pm 1.5$ & $<0.001$ & $<0.001(0.672,0.564-0.799)$ \\
\hline Embolism to distal or different site, no. (\%) & $4(2.3)$ & $5(2.0)$ & 0.999 & \\
\hline Additional urokinase, no. (\%) & $12(6.8)$ & $9(3.6)$ & 0.171 & 0.512 \\
\hline Additional GP, no. (\%) & $17(9.7)$ & $34(13.4)$ & 0.289 & \\
\hline Recanalization, no. (\%) & $121(68.8)$ & $2232(88.1)$ & $<0.001$ & $0.001(2.935,1.525-5.650)$ \\
\hline
\end{tabular}




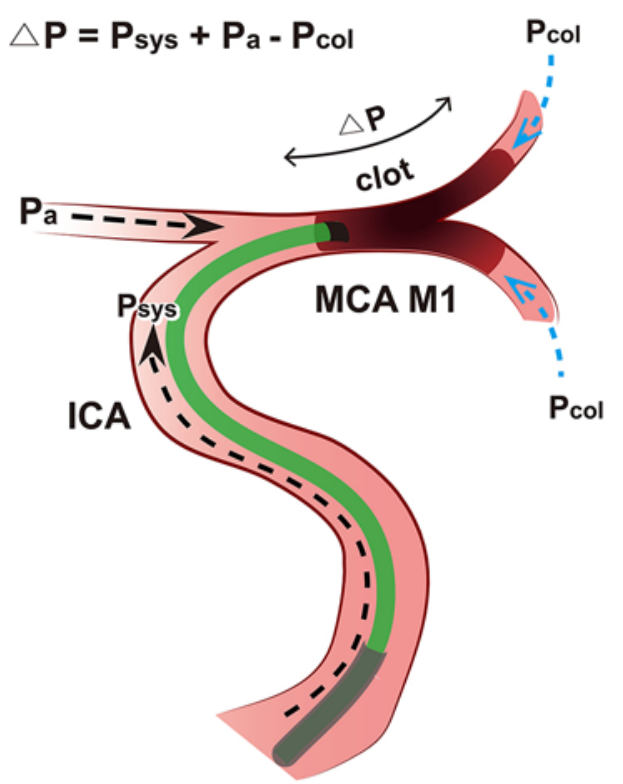

A: non-BGC

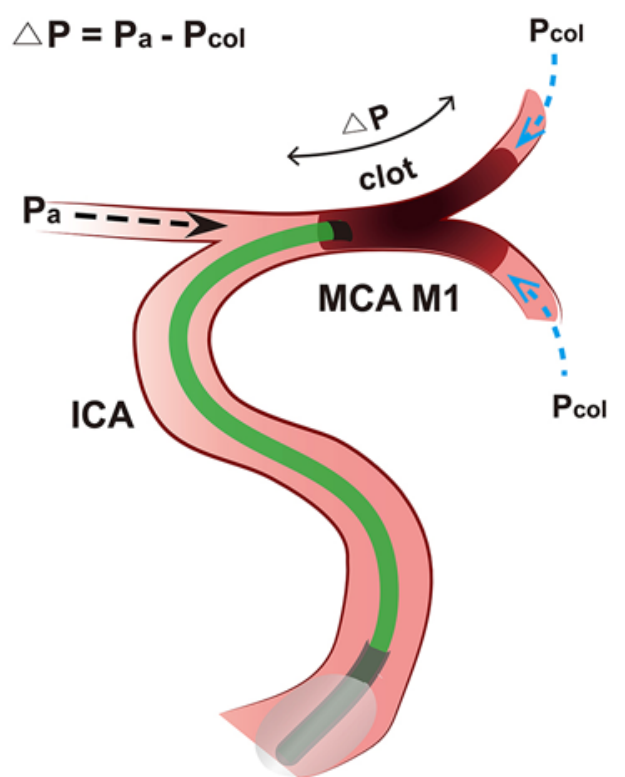

B: BGC

FIG. 2. Drawings of a comparison between non-BGC and $B G C$ in affecting the pressure gradient $(\triangle P)$ across the occluding clot. A: Contact aspiration thrombectomy under non-BGC: $\Delta P=P_{s y s}+P_{a}-P_{c o l}$. B: Contact aspiration thrombectomy under balloon inflation of $B G C: \Delta P=P_{a}-P_{c o l}$. Inflation of the balloon lowers systemic pressure acting on the proximal surface of the occluding clot, resulting in a decrease in the pressure gradient across the clot. $\Delta \mathrm{P}=$ pressure gradient across the occluding clot; $P_{\text {sys }}=$ systemic blood pressure acting on the proximal surface of the clot; $P_{a}=$ pressure acting on the proximal surface by collateral flow via the anterior communicating artery; $P_{\text {col }}=$ pressure acting on the distal surface of the clot by leptomeningeal collateral blood flow. Figure is available in color online only.

in the pressure gradient across the clot (Fig. 2). ${ }^{13}$ This can enhance the function of an aspiration catheter, as well as a stent retriever, as shown in the results of this study.

It has been suggested that the simultaneous use of an aspiration catheter and a stent retriever, previously called the "Solumbra technique," may increase the recanalization rate and reduce distal embolization. ${ }^{7,11} \mathrm{~A}$ recent $\mathrm{RCT}$ showed that the mTICI grade $2 b-3$ recanalization rate was $81.9 \%$ with the simultaneous use of an aspiration catheter and 3D stent retriever and $69.8 \%$ with an aspiration catheter alone (difference: $12.1 \%$; 95\% CI 2.0\%-22.2\%), although the good outcome rate showed no difference $(45.3 \%$ vs $45.8 \%) .{ }^{17}$ In our study, the overall recanalization rate was $80.2 \%$, of which $67.1 \%$ was achieved with CAT alone and $13.0 \%$ was achieved with a switch to or the simultaneous use of a stent retriever after the failure of CAT alone (Fig. 1). In other words, of the 141 patients who did not have recanalization with CAT alone, 86 were treated with a switch to or the simultaneous use of a stent retriever and CAT. Of them, 65.1\% (56 of 86) experienced recanalization success. Besides the use of BGC for increasing recanalization rates, one may consider a switch to or initial combination of CAT with a stent retriever. These results warrant a further prospective study in a large population to compare the outcomes of the combined use of CAT and a stent retriever and those with the use of CAT alone or a stent retriever alone.

This study has several limitations and strengths. Since all the CATs in this study were based on manual aspiration, the effect of BGC utilization on CAT might be different in the setting of aspiration pump during CAT. The results of the study should be interpreted with caution because they might be influenced by selection bias. However, the study population was recruited from the prospectively maintained registry of each participating center. Furthermore, the two patient groups showed a balanced distribution of clinical variables, including stroke risk factors, except for atrial fibrillation and dyslipidemia. Therefore, clinical factors seemed less likely to affect the major findings of our analysis. Of the preprocedural factors, baseline NIHSS score and incidence of distal ICA involvement were significantly higher in the BGC group than in the non-BGC group, whereas $\mathrm{M}_{2}$ occlusion alone was higher in the non-BGC group. Higher NIHSS score and ICA involvement seemed to negatively affect the outcomes of the BGC group. ${ }^{2}$ In addition, although not significant, the incidence of tandem occlusion, which was independently associated with a poor outcome in this study (and was a negative factor associated with recanalization rate in another recent study ${ }^{2}$ ), was more frequent in the BGC group than in the non-BGC group. On the contrary, the $\mathrm{M}_{2}$ occlusion alone that was higher in the non-BGC group was suggested as a good prognostic factor. Nevertheless, the BGC group had a significantly better recanalization rate and clinical outcomes than the non-BGC group. It seems that the favorable effects of BGC use outweighed the potential disadvantages of those factors. As a result, the use of BGC remained independently associated with recanalization success, after adjustment for other potential prognostic factors. The results of this study may be helpful in the setting of EVT for acute stroke and may provide baseline data for further prospective study designs. 


\section{Conclusions}

Utilization of BGCs reduced CAT procedure time, the number of passes, distal emboli during CAT, and the need for the adjunctive use of thrombolytics, whereas it increased the final and first-pass recanalization rates. As a result, the use of BGCs was independently associated with recanalization success.

\section{Acknowledgments}

This research was supported by a grant from the Korea Health Technology R\&D Project through the Korea Health Industry Development Institute (KHIDI), funded by the Ministry of Health \& Welfare, Republic of Korea (HC15C1056).

\section{References}

1. Berkhemer OA, Fransen PS, Beumer D, van den Berg LA, Lingsma HF, Yoo AJ, et al: A randomized trial of intraarterial treatment for acute ischemic stroke. N Engl J Med 372:11-20, 2015

2. Blanc R, Redjem H, Ciccio G, Smajda S, Desilles JP, Orng $\mathrm{E}$, et al: Predictors of the aspiration component success of a direct aspiration first pass technique (ADAPT) for the endovascular treatment of stroke reperfusion strategy in anterior circulation acute stroke. Stroke 48:1588-1593, 2017

3. Campbell BC, Mitchell PJ, Kleinig TJ, Dewey HM, Churilov L, Yassi N, et al: Endovascular therapy for ischemic stroke with perfusion-imaging selection. N Engl J Med 372:1009_ 1018, 2015

4. Chueh JY, Kühn AL, Puri AS, Wilson SD, Wakhloo AK, Gounis MJ: Reduction in distal emboli with proximal flow control during mechanical thrombectomy: a quantitative in vitro study. Stroke 44:1396-1401, 2013

5. Goyal M, Demchuk AM, Menon BK, Eesa M, Rempel JL, Thornton J, et al: Randomized assessment of rapid endovascular treatment of ischemic stroke. N Engl J Med 372:10191030,2015

6. Goyal M, Menon BK, van Zwam WH, Dippel DW, Mitchell PJ, Demchuk AM, et al: Endovascular thrombectomy after large-vessel ischaemic stroke: a meta-analysis of individual patient data from five randomised trials. Lancet 387:17231731,2016

7. Humphries W, Hoit D, Doss VT, Elijovich L, Frei D, Loy D, et al: Distal aspiration with retrievable stent assisted thrombectomy for the treatment of acute ischemic stroke. J Neurointerv Surg 7:90-94, 2015

8. Jahan R: Solitaire flow-restoration device for treatment of acute ischemic stroke: safety and recanalization efficacy study in a swine vessel occlusion model. AJNR Am J Neuroradiol 31:1938-1943, 2010

9. Jovin TG, Chamorro A, Cobo E, de Miquel MA, Molina CA, Rovira A, et al: Thrombectomy within 8 hours after symptom onset in ischemic stroke. N Engl J Med 372:2296-2306, 2015

10. Kang DH, Hwang YH, Kim YS, Park J, Kwon O, Jung C: Direct thrombus retrieval using the reperfusion catheter of the penumbra system: forced-suction thrombectomy in acute ischemic stroke. AJNR Am J Neuroradiol 32:283-287, 2011

11. Kang DH, Kim YW, Hwang YH, Park J, Hwang JH, Kim YS: Switching strategy for mechanical thrombectomy of acute large vessel occlusion in the anterior circulation. Stroke 44:3577-3579, 2013

12. Kang DH, Park J: Endovascular stroke therapy focused on stent retriever thrombectomy and direct clot aspiration: historical review and modern application. J Korean Neurosurg Soc 60:335-347, 2017

13. Kim BM: Causes and solutions of endovascular thrombectomy failure. J Stroke 19:131-142, 2017

14. Lapergue B, Blanc R, Gory B, Labreuche J, Duhamel A, Marnat G, et al: Effect of endovascular contact aspiration vs stent retriever on revascularization in patients with acute ischemic stroke and large vessel occlusion: the ASTER randomized clinical trial. JAMA 318:443-452, 2017

15. Manning NW, Chapot R, Meyers PM: Endovascular stroke management: key elements of success. Cerebrovasc Dis 42:170-177, 2016

16. Nguyen TN, Malisch T, Castonguay AC, Gupta R, Sun CH, Martin CO, et al: Balloon guide catheter improves revascularization and clinical outcomes with the Solitaire device: analysis of the North American Solitaire Acute Stroke Registry. Stroke 45:141-145, 2014

17. Nogueira RG, Frei D, Kirmani JF, Zaidat O, Lopes D, Turk AS III, et al: Safety and efficacy of a 3-dimensional stent retriever with aspiration-based thrombectomy vs aspirationbased thrombectomy alone in acute ischemic stroke intervention: a randomized clinical trial. JAMA Neurol 75:304-311, 2018

18. Saver JL, Goyal M, Bonafe A, Diener HC, Levy EI, Pereira VM, et al: Stent-retriever thrombectomy after intravenous t-PA vs. t-PA alone in stroke. N Engl J Med 372:2285-2295, 2015

19. Stampfl S, Pfaff J, Herweh C, Pham M, Schieber S, Ringleb PA, et al: Combined proximal balloon occlusion and distal aspiration: a new approach to prevent distal embolization during neurothrombectomy. J Neurointerv Surg 9:346-351, 2017

20. Velasco A, Buerke B, Stracke CP, Berkemeyer S, Mosimann PJ, Schwindt W, et al: Comparison of a balloon guide catheter and a non-balloon guide catheter for mechanical thrombectomy. Radiology 280:169-176, 2016

21. Wei D, Mascitelli JR, Nistal DA, Kellner CP, Fifi JT, Mocco $\mathrm{JD}$, et al: The use and utility of aspiration thrombectomy in acute ischemic stroke: a systematic review and meta-analysis. AJNR Am J Neuroradiol 38:1978-1983, 2017

22. Yoo AJ, Andersson T: Thrombectomy in acute ischemic stroke: challenges to procedural success. J Stroke 19:121130,2017

\section{Disclosures}

The authors report no conflicts of interest concerning the materials or methods used in this study or the findings specified in this paper.

\section{Author Contributions}

Conception and design: BM Kim. Acquisition of data: all authors. Analysis and interpretation of data: BM Kim, Kang, Heo, Nam, YD Kim, Kwak, SH Kim. Drafting the article: BM Kim, Kang, Heo, Nam, YD Kim, Hwang, YW Kim, YS Kim, DJ Kim, Kwak, Roh, Lee. Critically revising the article: BM Kim, Kang. Reviewed submitted version of manuscript: all authors. Statistical analysis: BM Kim. Administrative/technical/material support: BM Kim. Study supervision: BM Kim.

\section{Correspondence}

Byung Moon Kim: Yonsei University College of Medicine, Seoul, South Korea.bmoon21@hanmail.net. 